\title{
Comportamento empreendedor: um estudo empírico baseado no referencial de McClelland
}

\section{Resumo}

Os estudos desenvolvidos por McClelland na década de 1960 contribuíram para descaracterizar a visão - até então dominante - que concebia a existência de uma personalidade empreendedora e atribuía aos traços empreendedores um caráter interno aos indivíduos. Apontavam tais estudos, então, para um conjunto de características psicossociais que explicavam a preferência de alguns indivíduos por um "estilo de vida sem patrão" (McClelland, 1987).

Baseado no conceito de motivação para a realização, esse autor se utilizou extensivamente da análise de estórias suscitadas pelas pranchas do TAT (Thematic Apperception Test), concluindo que empreendedores eram aqueles indivíduos que, dotados de um alto índice desse tipo de motivação, eram predispostos a correr riscos e buscar a excelência no fazer, além de possuírem lócus de controle interno.

Este trabalho tem por base os conceitos de McClelland à luz de pesquisas de décadas subsequentes e apresenta os resultados da aplicação do método de McClelland a um grupo de aproximadamente 20 empreendedores ligados a um Centro Incubador de Empresas, em São Paulo, em 2005 (Barlach, 2007), e a um grupo de 6 (seis) empreendedores ligados à Incubadora Tecnológica e Social da EACH USP, em 2012. Os instrumentos utilizados na primeira pesquisa foram o TAT (aplicado individualmente, seguido de discussão orientada em pequenos grupos), o inventário LOC (para avaliar o lócus de controle) e a observação do comportamento individual e grupal ao longo de um ciclo de aulas coordenado pela autora. Quanto à segunda pesquisa, o instrumento básico foi a aplicação do TAT, com a análise das estórias e a discussão coletiva dos resultados, seguida da elaboração de planos de trabalho individuais (PDIs).

Os resultados indicam que a decisão de empreender não tem relação biunívoca com a presença do comportamento empreendedor, conforme o referencial de McClelland, e que a elaboração de PDIs pode colaborar para a identificação das lacunas entre as competências comportamentais existentes no momento da decisão de empreender e as que deverão ser objeto de reflexão e investimento pessoal ou coletivo das diversas fases até a implementação do novo negócio.

Palavras-chave: comportamento empreendedor, planos de desenvolvimento individual, TAT (Thematic Apperception Test).

\section{Entrepreneurial behaviour: an empiric study based on the McClelland reference}

\section{Abstract}

Studies developed by McClelland in the 60's contributed to mischaracterize the vision - until then - dominant- who conceived the existence of an entrepreneurial personality and attributed entrepreneurs' traits to an internal character of individuals. Such studies pointed, then, to a set of psychosocial characteristics that explain the preference of some individuals for a "lifestyle without boss" (McClelland, 1987).

\footnotetext{
${ }^{1}$ Professora da Escola de Artes, Ciências e Humanidades da Universidade de São Paulo. (liseteb@fia.com.br)
} 
Based on the concept of motivation to achieve, this author has extensively used the analysis of stories raised by images of TAT (Thematic Apperception Test), concluding that entrepreneurs were those individuals who, endowed with a high level of this kind of motivation, were predisposed to take risks and seek excellence in doing, in addition to possessing internal locus of control.

This paper analyzes the concepts of McClelland throughout the lens of subsequent decades research and presents the results of applying the method of McClelland to a group of approximately 20 entrepreneurs connected to a Business Incubator Center, in São Paulo, in 2005 (Barlach, 2007), and a group of 6 (six) entrepreneurs linked to Technological and Social Incubator EACH USP in 2012. The instruments used in the first study were the TAT (applied individually, followed by targeted discussion in small groups), the LOC inventory (to assess locus of control) and the observation of individual and group behavior alongside a cycle of classes coordinated by author. For the second survey, the basic instrument was the application of TAT, with analysis of the stories and the collective discussion of the results, followed by the development of individual work plans.

The results indicate that the decision to undertake has no univocal relationship with the presence of entrepreneurial behavior, as described by McClelland, and the elaboration of individual plans can collaborate for the identification of gaps between the existing behavioral skills at the time of the decision to undertake and what should be the object of reflection and personal or collective investment.

Keywords: entrepreneurship behavior, individual development plans, TAT (Thematic Apperception Test).

\section{Introdução}

Ao proceder a um estudo sobre o comportamento empreendedor, constata-se o grande número de menções às pesquisas desenvolvidas por David McClelland nas décadas de 1960 e 1970. Uma breve revisão da literatura aponta que os estudiosos - do passado e do presente - apoiam-se em conceitos introduzidos por ele para referenciar suas pesquisas.

O autor (McClelland, 1987) foi um dos pioneiros nos estudos sobre a motivação humana e procedeu a inúmeros experimentos e pesquisas que buscaram entender a chamada "necessidade de realização" que estaria na base do comportamento empreendedor. Sua hipótese básica também entendia essa necessidade como responsável, em grande parte, pelo desenvolvimento econômico de uma região / país.

Para ele, não havia relação consistente entre genética e empreendedorismo, mas, sim, entre meio ambiente e empreendedorismo. A necessidade de realização seria desenvolvida a partir da cultura, das experiências e da aprendizagem. Os traços que caracterizariam os empreendedores não seriam "constitucionais", mas sim "moldados pelo ambiente" (McClelland, 1968). Em função destes pressupostos, o autor investigou tanto indivíduos quanto sociedades empreendedoras - do presente e do passado - procurando desvendar seus motivos realizadores. McClelland se contrapõe a algumas visões predominantes em épocas anteriores à sua segundo as quais o desenvolvimento econômico de um país poderia ser explicado por fatores climáticos ou pela superioridade de uma raça, aproximando-se, nesse sentido, de um referencial característico da Psicologia Social.

\footnotetext{
${ }^{1} \mathrm{~N}$-achievement: need for achievement, aqui traduzida como necessidade de realização.
} 


\section{A transformação do trabalho humano, a crise do emprego e o em- preendedorismo}

A retomada do interesse pelo tema do empreendedorismo ocorre quase simultaneamente à crise do emprego no período pós-industrial. Em 1995, Bridges comentava que "a estabilidade de emprego está atravessando uma dessas redefinições fundamentais que marca um ponto decisivo nas sociedades" (Bridges, 1995, grifos do autor). A precariedade e a temporariedade tornaram-se algumas das marcas do final do século XX e começo do século XXI. O próprio significado das palavras serviço (job) e emprego (employment) tem sido debatido, num contexto em que a linha divisória entre o trabalhador autônomo e o "trabalhar como empregado" tornou-se menos nítida. As novas tecnologias de comunicação que possibilitam o teletrabalho e os diferentes tipos de contratos de trabalho, prevendo horários flexíveis e o incremento do mercado informal de trabalho, são alguns dos aspectos que compõem o cenário atual.

Nesse contexto, em que as formas tradicionais do trabalho são impactadas pelo cenário de rupturas e mudanças, constata-se que "o empreendedor [tendo sido precedido pelo artesão, o profissional liberal e o executivo] é o modo mais recente de um elenco de formas que têm caracterizado a evolução da institucionalização do trabalho" (Malvezzi, sem data).

Segundo o autor, destacam-se alguns elementos da evolução histórica do trabalho artesanal ao empreendedor:

"Até o final do século XVIII, a forma mais comum e predominante de trabalho era o artesanato. $O$ artesão caracterizava-se pelo conhecimento prático e técnico de algum material [...] e controle sobre os meios de produção. Seu principal desafio era idealizar formas e materializá-las na matéria prima. Os clientes eram relativamente estáveis em seus valores, expectativas e necessidades. [...] Nessa época, a necessidade e o ideal na vida de todo o jovem era dominar habilidades manuais relativas a uma dessas matérias primas. A competência artesanal aprendida no próprio lar constituía-se na base da segurança social."

Passa-se, então, à fase da industrialização.

"A partir do século XIX, com a rápida industrialização, a produção de bens materiais, até então artesanais, começou a migrar para o chão de fábrica. Se um artesão demorava três dias para produzir uma cadeira, a fábrica passou a produzir trezentas cadeiras por dia. A potencialidade das fábricas era produzir [...] de modo mais rápido e mais barato [...]. Encurralado pela competição com a fábrica, o artesanato entrou em declínio e a mão de obra migrou para as indústrias."

"[...] Nos primeiros cinquenta anos do século XX, em paralelo à forma de emprego operário, a sociedade abrigou o crescimento dos profissionais liberais; [apresentando] um perfil ocupacional polarizado por dois núcleos; um direcionado para as fábricas e organizações (o emprego) e outro direcionado para esses serviços independentes (os profissionais liberais). Através desses dois polos caracterizavam-se duas alternativas de carreira, uma dentro e outra fora das empresas."

O autor conclui:

"[...] Com a teleinformação, cresceram os índices de produtividade. Teve início uma nova era, caracterizada pelo excedente de oferta em relação à demanda. Hoje, há mais produtos e serviços disponíveis do que clientes para comprá-los. Podendo escolher, o cliente foi aprendendo a ser mais exigente, simplesmente porque ele dispunha de mais alternativas e poderia obter o produto mais próximo de suas necessidades e valores. A sobrevivência e o sucesso nos negócios dependiam da capacidade de satisfação das expectativas dos clientes. Administrar deixou de ser o cuidado com os problemas contidos dentro das quatro paredes da empresa e passou a ser a capacidade de identificar os valores e expectativas do cliente e de transformá-los em características (qualidades) do produto, ou ser- 
viço. Essa transformação exigia uma nova empresa (mais flexível e descentralizada) e um novo trabalhador (mais controlador do processo de transformação e mais comprometido com o cliente). As empresas foram se ajustando à gestão por projetos e o trabalhador foi se metamorfoseando no empreendedor. [...] A institucionalização do trabalho sofria nova alteração, [levando] à forma de trabalho predominante hoje que é a do empreendedor."

Se o cenário econômico-social explica o advento do perfil intraempreendedor que caracteriza hoje os profissionais que atuam dentro das empresas, outros elementos auxiliam a compreensão do empreendedor, desejoso de abrir o seu próprio negócio e viver "uma vida sem patrão". Embora não se tenha mencionado o aspecto desemprego, é certo que este é um dos fatores-chave que compõem este cenário, ainda que muitos autores discutam se ele pode ser denominado desemprego estrutural e se a introdução acelerada de novas tecnologias em inúmeros setores econômicos tenderá a substituir o elemento humano e mesmo se o desemprego é o motivador principal para a abertura de novos negócios (Wright et al., 2010).

Viver o sonho de "ter seu próprio negócio" tem sido, então, incentivado por governos e países como alternativa para a inserção humana na vida produtiva.

\section{Motivação para realização e empreendedorismo em McClelland}

De acordo com McClelland, o comportamento empreendedor é consequência das variáveis cognitivas do aprendizado social que são produto da história de cada indivíduo e que, por sua vez, regulam novas experiências ou as afetam.

Para o autor, são características das pessoas motivadas para a realização: a) a capacidade de estabelecer objetivos altos, mas alcançáveis; b) a preocupação com realização pessoal ao invés de recompensas - extrínsecas - pelo sucesso; c) o desejo de feedback relevante sobre o trabalho (como estou me saindo?), ao invés de feedback atitudinal (quanto você gosta de $\operatorname{mim}$ ?).

O primeiro item possibilita diferenciar o comportamento empreendedor de certos neuroticismos que desconsideram as possibilidades reais de alcançar as metas propostas, e a consequente realização das mesmas no plano dos delírios e fantasias. O tópico b foi retomado por inúmeros autores posteriores a McClelland que, em suas pesquisas, confirmaram a importância da motivação intrínseca para o alcance de metas (Amabile, 1996). O terceiro tópico remete ao domínio atitudinal do comportamento e é um corolário da presença da motivação intrínseca, em que o indivíduo não valoriza os aspectos objetivos da avaliação externa.

McClelland acrescenta, ainda, à descrição do comportamento empreendedor e da motivação para realização os seguintes elementos: o impulso para a excelência, ou seja, o alcance de um objetivo em relação a conjunto de padrões; o querer fazer bem um trabalho ou realizar algo importante; o desejo de responsabilidade pessoal para achar soluções para problemas; o gosto pelo feedback rápido sobre performance (de forma a ter elementos para o próprio aperfeiçoamento); o evitar aquilo que é muito fácil ou muito difícil; o não gostar do sucesso como produto do acaso; e a preferência por desafios que não estejam acima de suas capacidades.

Ele conclui que se trata de uma estrutura motivacional dos que procuram o auto emprego como forma de vida ou como estilo de vida alternativo.

Naquilo que concerne ao lócus de Controle (LC), comenta que os (as) empreendedores (as), possuiriam a crença de que têm controle sobre o seu destino, o que caracteriza o LC interno. Observa que os proprietários (as) e empresários (as) apresentam, predominantemente, o LC interno, segundo a escala proposta por Bastos (1991) o mesmo ocorrendo com executivos (as) e gerentes sênior. Diz ainda que o lócus de controle externo ou interno impacta a tomada 
de decisões, resultando em maior conservadorismo no caso de LC externo e na adoção de estratégias imaginativas, maior inventividade, no caso de LC interno.

\section{Definição de empreendedor}

A definição de empreendedorismo e a caracterização do (a) empreendedor (a) não alcança consenso na literatura. Seria ele (ela) aquele (a) que "abre um negócio"? Ou talvez aquele (a) que toma iniciativas, identifica oportunidades, resolve problemas de forma eficaz?

Os estudos de Cardon et al. (2009) e Rindova et al. (2009) consideram os distintos aspectos do comportamento empreendedor, que podem se expressar em diferentes momentos do processo ou como distintas "identidades". O momento de detecção de novas oportunidades, por exemplo, é distinto do momento da criação de uma nova organização. Os papéis empreendedores - ser um inventor, um fundador ou um desenvolvedor - também ganham expressão nos dois trabalhos. Barlach \& Malvezzi (2012, p. 6) discutem esta questão questionando se a existência desses diferentes focos identititários pode explicar o porquê dos (as) empreendedores (as) que evidenciam alta paixão quando o negócio estava nascendo perdem-na à medida que o negócio cresce, por que alguns apaixonados por sua ideia abrem mão dela para que outros desenvolvam o negócio e extraiam valor deste crescimento, ou porque alguns continuam e persistem enfrentando todo tipo de obstáculo e impedimento, enquanto outros (as) desistem.

Ao definir o empreendedor, portanto, cabe diferenciá-lo de outros tipos de proprietários de negócios e de outras atividades profissionais, tais como empresários, proprietários ou donos, executivos, gerentes e também identificar se se trata de fundador ou não, pois as pesquisas indicam que empresários estabelecidos correm riscos mais moderados e McClelland não pretendia descrever as características do dono de um negócio, mas do empreendedor em si. O autor afirma que o empreendedorismo é, além de uma atividade econômica, uma forma de arte, a opção por um estilo de vida sem patrão.

\section{Perfil do empreendedor}

É importante ressaltar que, embora a orientação para eficiência, a preocupação com alta qualidade do trabalho, o planejamento e monitoramento sistemático e o reconhecimento da importância das relações de negócios sejam comuns às pessoas com alto nível de motivação para a realização, não existe acordo entre pesquisadores sobre o perfil psicológico do empreendedor. Há uma falsa ideia de uniformidade, mas os indicam que os empreendedores não são grupo homogêneo. Além disso, um único tipo psicológico não conseguiria abarcar as diferenças de forma de operar e de sucesso ou fracasso por parte de empreendedores. Logo, pode-se afirmar que não existe um empreendedor ideal, mas diferentes tipos de empreendedores, com diferentes características de personalidade e estilos de empreender.

De forma geral, há algum consenso indicando que a sensação de estar permanentemente sob pressão e apresentar extremos de competitividade, agressividade, impaciência, e luta pela realização seriam alguns elementos do perfil empreendedor.

\section{Os instrumentos de McClelland para mensuração da motivação}

McClelland $(1953,1987)$ pressupunha que a motivação para a realização pudesse ser suscitada a partir de determinados tipos de instrução que estimulassem os sujeitos da pesquisa a demonstrar comportamentos associados a esta motivação. Assim, antes de aplicar o TAT a jovens universitários que constituíam a população de seu estudo, McClelland os informava de que os resultados no teste constituiriam fator de progresso escolar, o que, indiretamente 
poderia levá-los a aplicar-se no teste.

Além disso, comparou um grupo de 12 empreendedores bem sucedidos e 12 empreendedores com desempenho mediano, aplicando o Behavioral Event Interview (BEI), solicitando aos respondentes que relatassem incidentes críticos e episódios da vida do negócio.

Estudou os contos folclóricos das culturas "primitivas", de forma a entender se eles contêm imagens de empreendedorismo quando provém de tribos com maior atividade econômica. Investigou também histórias contadas a alunos de $3^{\mathrm{a}}$ ou $4^{\mathrm{a}}$ série - que estavam aprendendo a ler -, comparando-as ao índice de n-achievement num determinado país, em períodos diferentes de desenvolvimento econômico. Verificou, na literatura do passado, se as imagens de empreender são mais frequentes antes de períodos de desenvolvimento econômico rápido. Analisou a relação entre o n-achievement e as atitudes parentais, verificando que a antecipação da independência por parte, sobretudo, das mães com relação a seus filhos, influenciava a escolha pelo empreendedorismo. O presente estudo utilizou-se parcialmente deste referencial, como descrito adiante.

\section{Metodologia: replicando o experimento de McClelland em 2005 e em 2012}

De natureza qualitativa, a pesquisa teve caráter exploratório - descritivo, utilizando-se de aplicação de inventários, realização de entrevistas semiestruturadas e pesquisa-ação.

Tendo em vista as referências teóricas apresentadas e o contexto no qual se insere o empreendedorismo no momento atual, iniciou-se a presente pesquisa pela identificação dos sujeitos que poderiam ser caracterizados como empreendedores.

Uma vez que as incubadoras de empresas são um dos componentes do cenário do empreendedorismo atual e que, para ser aceita como empresa incubada, diversos tipos de avaliação selecionam os empreendedores, optou-se por replicar o experimento de McClelland junto a um grupo da população de empreendedores das empresas incubadas na cidade de São Paulo.

Numa classe formada por proprietários de empresas incubadas e colaboradores destas, que participou de um Curso de Gestão de Pessoas ministrado pela autora, foram aplicados os seguintes instrumentos:

- TAT - Thematic Apperception Test

- Entrevistas

As histórias suscitadas pelas pranchas do TAT foram submetidas ao grupo de empreendedores e a dois juízes "isentos", para que estes opinassem sobre o motivo predominante nas histórias, a partir do referencial de Kolb (1990), acima descrito.

Utilizaram-se ainda entrevistas não-estruturadas e observação do comportamento individual e grupal dos sujeitos da pesquisa.

Ao final de cada um dos processos acima descritos, os participantes foram orientados para a elaboração de Planos de Desenvolvimento Individual, com o estabelecimento de metas de desenvolvimento ou aprimoramento das competências empreendedoras. 


\section{Analisando a motivação empreendedora por meio do TAT - The- matic Apperception Test}

Com o uso do TAT, podem-se obter respostas referidas a três tipos de motivação: realização, poder e associação. Segundo Kolb (1990, p. 71-72), a motivação para a realização pode ser inferida nas histórias do TAT quando "alguém na história está preocupado com um padrão de excelência: quer ganhar ou fazer bonito numa competição; possui padrões auto impostos para um bom desempenho ou está emocionalmente envolvido na obtenção de um objetivo de realização".

Ainda segundo ele, "padrões de excelência podem ser inferidos pelo uso de palavras tais como bom ou melhor, [...], quando da avaliação de um desempenho". Destaca, nesse sentido, quando "alguém na história está envolvido na realização de algo único, tal como uma invenção ou uma criação artística ou está envolvido num objetivo a longo prazo, tal como seguir uma carreira específica ou ser um sucesso na vida".

A motivação para o poder, por sua vez, está presente na história quando identificada uma das situações descritas a seguir:

Alguém na história é afetado ou emocionalmente envolvido na obtenção ou manutenção do controle dos meios para influenciar uma pessoa. Afirmações ligadas ao desejo de ensinar ou inspirar fazem parte desta categoria motivacional

Alguém está realmente fazendo algo para obter ou manter o controle dos meios de influenciar, tais como argumentar, exigir ou forçar, dar uma ordem, tentar convencer ou punir.

Existe uma afirmação de um relacionamento interpessoal que é definida como aquele em que um superior tem controle para influenciar um subordinado. A relação pai - filho não é classificada como relação de poder.

Finalmente, a motivação associativa está presente nas histórias do TAT quando "alguém na história está preocupado com o estabelecimento, a manutenção ou a restauração de uma relação emocional positiva com outra pessoa, existem afirmações de que uma pessoa gosta ou quer ser querida por outra ou que alguém tem um sentimento semelhante por outrem ou, ainda, se a história menciona atividades associativas como festas, reuniões, visitas ou batepapos descontraídos".

Kolb (1990) propõe uma metodologia de trabalho com as histórias elaboradas a partir do TAT, em que um grupo se reúne e utiliza os parâmetros acima para avaliar as estórias dos demais colegas e receber feedback sobre suas próprias motivações. Esta técnica foi utilizada na atual pesquisa, cujos resultados serão apresentados a seguir.

\section{Resultados do presente estudo}

Na primeira etapa da pesquisa, em 2005, vinte pessoas submeteram-se ao TAT, escrevendo histórias sobre seis pranchas, totalizando 120 histórias, que foram, então analisadas pelo grupo e, posteriormente, enviadas a três juízes que não tiveram contato com os sujeitos e receberam as histórias e os critérios para julgá-las (Kolb, 1990). Os resultados de todas as pranchas, obtidos pela compilação final dessas análises, indicaram:

Motivação para a realização - 77 respostas

Motivação para o poder - 28 respostas

Motivação para a associação - 15 respostas 
Não foi realizada a análise comparativa prancha a prancha que poderia apontar outros elementos das diferentes motivações suscitadas. As entrevistas e observações complementares à aplicação do TAT apontaram para a predominância da motivação para a realização. As demais respostas poderiam indicar elementos comportamentais que necessitam ser equilibrados, uma vez que este grupo de empreendedores está em processo de criação de seu próprio negócio (em um centro de incubação de negócio). Poderiam também ser considerados traços ou estilos de personalidade que não são compatíveis com a motivação para a realização.

Na segunda etapa da pesquisa, em 2012, o TAT foi aplicado a seis empreendedores (as) e as histórias resultantes foram analisadas pelos próprios participantes, a partir dos critérios propostos por Kolb. Os resultados não indicaram o predomínio de um único tipo de motivação, com duas respostas indicando a motivação para o poder, duas em que predominou a associação, uma deles claramente indicativa da motivação para a realização e uma em que o grupo não conseguiu consenso sobre qual a motivação predominante.

Nos dois momentos da pesquisa, a discussão foi seguida de orientações para a elaboração de Planos de Desenvolvimento Individual, com o estabelecimento de metas de desenvolvimento ou aprimoramento das competências empreendedoras, que pudessem contribuir para seu autoconhecimento, bússola norteadora, do ponto de vista comportamental, para os enfrentamentos necessários ao longo do processo de empreender.

\section{Análise dos resultados}

Com relação aos resultados devem ser feitas algumas ressalvas. Em primeiro lugar, tratando-se de uma pesquisa qualitativa de natureza exploratória, não há possibilidades de generalizá-los.

Embora os instrumentos e as técnicas de pesquisa propostas por McClelland (1987, 1953) tenham se revelado adequadas à compreensão do comportamento empreendedor, a elaboração dos planos de desenvolvimento individual que devem complementar a intervenção junto a grupos de empreendedores (as) apresenta inúmeras dificuldades para sua elaboração, comprometendo, por vezes, a proposta interventiva. Em outras palavras, os indivíduos que participam desse tipo de oficina desenvolvem a expectativa em relação a seu autoconhecimento e também aos planos e às ações de autodesenvolvimento e a duração das oficinas nem sempre é suficiente para as orientações necessárias à sua elaboração.

Em função disso, sugere-se que, entre a aplicação dos instrumentos (TAT e entrevistas grupais) e a elaboração do Plano de Desenvolvimento Individual, seja reservado um tempo de aproximadamente uma semana para, então, realizar nova reunião grupal para discussão dos mesmos.

Um dos aspectos que mais chamou a atenção durante as entrevistas e discussões grupais que se seguiram à aplicação do TAT foi relativo às atitudes parentais próprias ou das famílias de origem. Segundo McClelland (1968), o elemento de antecipação da independência por parte, sobretudo, das mães com relação a seus filhos, influenciava a escolha futura pelo caminho empreendedor. Tendo os dois estudos sido realizados na cidade de São Paulo, tida como "perigosa", dado que seus habitantes estão expostos a inúmeros riscos à segurança e integridade pessoal, a mencionada antecipação da independência não pôde, muitas vezes, ser praticada, embora tenha sido fator de discussão e fonte de aprendizagem ao longo do desenvolvimento pessoal dos participantes. 


\section{Conclusões}

Embora o cenário socioeconômico atual seja substancialmente distinto daquele no qual McClelland realizou suas pesquisas, os resultados indicam que a proposição do autor sobre a associação entre a motivação para a realização e o comportamento empreendedor ainda são atuais.

Os estudos sobre o comportamento empreendedor, além de se beneficiarem com a adoção desse referencial, podem contribuir para a compreensão das competências comportamentais que agregam valor ao diferencial competitivo de um negócio.

\section{Referências Bibliográficas}

AMABILE, Teresa (1996). Creativity in context: update to social psychology of creativity. Colorado, US: Westview Press.

BARLACH, Lisete (2007). Learning by self-knowledge. RJ (IBMEC): Roundtable for entrepreneurship education.

BARLACH, Lisete; Malvezzi, Sigmar (2012) Empreendedorismo interno e criação de empresas: transição ou mudança? São Paulo: ReCaPe Revista de Carreiras e Pessoas. V.02 n.02 Mai/Jun/Jul/Ago, p. 2-12.

BASTOS, Antonio V. B. (1991) Validação da escala locus de controle no trabalho de Spector 1988. Porto Alegre: Psico; 22(2): 133-154, jul-dez.

BRIDGES, William (1995) Um mundo sem empregos. SP: Makron Books.

Cardon et al. (2009) e Rindova et al. (2009)

CARDON, Melissa S.; WINCENT, Joakim; SINGH, Jagdip; DRNOVSEK, Mateja. The nature and experience of entrepreneurial passion. Academy of Management Review, v. 34, n. 3, p. 511-532, 2009.

MALVEZZI, Sigmar (manuscrito, sem data) A Formação do Empreendedor.

McCLELLAND, DAVID; STEELE, ROBERT (1987) Human motivation. NJ: General Learning Press.

McCLELLAND, DAVID (1968) La sociedad ambiciosa Vol. I e II. Madrid: Ediciones Guadarrama.

McCLELLAND, DAVID; ATKINSON, JOHN; CLARK, RUSSELL; LOWELL, EDGAR (1953) The achievement motive. NY, Appleton-Century-Crofts.

RINDOVA, Violina; BARRY, David; KETCHEN JR., David J. (2009) Entrepreneuring as emancipation. Academy of Management Review, v. 34, n. 3, p. 477-491.

WRIGHT, J. T. C.; SILVA, Antonio Thiago Benedete; SPERS, Renata Giovinazzo. (2010) O mercado de trabalho no futuro: uma discussão sobre profissões inovadoras, empreendedorismo e tendências para 2020. RAI Revista de Administração e Inovação, Vol. 7, n. 3. 